\title{
Sound Absorption Coefficient and Water Content Responses in Acoustic Analysis Based on Renewable Polyurethane Foam Composites
}

\author{
Hanani Abdul Wahab, Anika Zafiah M. Rus, M. F. L. Abdullah, Nur Munirah Abdullah
}

\begin{abstract}
In physiological health, negative effects are felt when unwanted noise is present. Given the negative effects of the unwanted noise, it become important to examine how environmentally-friendly and efficient sound absorbing materials could be developed. Some of the materials associated with acoustic absorption properties entail polymer foams. Particularly, the foams aid in controlling noise. The central purpose of this study was to examine renewable polymer (PU) foam composites' aspects of moisture content and acoustical properties. Four major parameters that were evaluated included the thickness of the sample, the type of filler, the ratio of the fillers, and the nature of the monomer. A design of experiment (DoE) technique was employed. To prepare the PUs foams, $28 \mathrm{~mm}$ and $100 \mathrm{~mm}$ were selected as diameters for the cylindrical shapes on focus. Plotting the main effects was achieved through ANOVA, upon which variations in the role and performance of the selected input factors were discerned. From the findings, it was established that when bio-epoxy (B) was used in conjunction with renewable PU foams, the moisture content was greater than the case involving petroleum based PU foam synthesis. Hence, renewable PU foam composite is seen to be realized at 0.9 , especially if the filler ratios and size are increased; with the experimental conditions set at 3 $\mathrm{kHz}$. Overall, the study established that the renewable Pus' state of sound absorption exhibits good agreement with the case of synthetic PU foam.
\end{abstract}

Index Terms: Acoustic; ANOVA; DoE; PU foams; Renewable

\section{INTRODUCTION}

Currently, one of the notable environmental pollutants is noise. With its associated negative effects on the health of the public, noise refers to an undesirable sound. The long-term effect entails impaired human lifestyle. Previous studies have focused on some of the methods through which acoustic systems could be improved, especially among sound absorbing materials that aid in improving the quality of human life [1-5]. The extent to which the sound absorbing

Revised Manuscript Received on July 22, 2019

Hanani Abdul WahabSustainable Polymer Engineering, Advanced Manufacturing and Materials Center (SPEN-AMMC), Faculty of Mechanical and Manufacturing, Universiti Tun Hussein Onn Malaysia, 86400 Parit Raja, Batu Pahat, Johor, Malaysia.

Anika Zafiah M. Rus,Sustainable Polymer Engineering, Advanced Manufacturing and Materials Center (SPEN-AMMC), Faculty of Mechanical and Manufacturing, Universiti Tun Hussein Onn Malaysia, 86400 Parit Raja, Batu Pahat, Johor, Malaysia.

M. F. L. Abdullah, Department of Communication Engineering, Faculty of Electrical and Electronic Engineering, Universiti Tun Hussein Onn Malaysia, 86400 Parit Raja, Batu Pahat, Johor, Malaysia.

Nur Munirah Abdullah, Sustainable Polymer Engineering, Advanced Manufacturing and Materials Center (SPEN-AMMC), Faculty of Mechanical and Manufacturing, Universiti Tun Hussein Onn Malaysia, 86400 Parit Raja, Batu Pahat, Johor, Malaysia. materials could absorb the sound form a major determinant of their categorization into various groups. In particular, the materials are expected to reflect minimal sound waves while ensuring that most of the waves (sound waves) are absorbed as desired [6].

Hence PU foams (flexible polyurethane) exhibiting high porosity have gained increasing use towards controlling noise. They have gained use in industrial scenarios because of their promising features or properties such as acoustic absorption properties, excellent viscoelasticity, being light in weight, and effective sound absorption [7, 8]. However, most of polyurethane (PU) foams are based of raw materials from petroleum. Nonetheless, recent environmental issue invokes studies on bio-based monomers such as palm oil and waste vegetable oil [9 -11]. Currently, issues of sustainability when using polymer foams arises thus movements towards the production of bio-based plastics and composites became an important aspect. Thus, advancement towards bio-foam is further focused for better sustainability options. Thus, advancement towards bio-foam is further focused for better sustainability options. Additionally, natural fiber use in relation to PU foam fabrication is increasing. The trend is associated with the modern technical developments that have led to the realization of more environmentally friendly and economical fiber processing techniques, as well as the biodegradable nature of the natural fibers [12-14].

The DoE experimental approach refers to a technique of solving problems systematically, especially in the engineering field. His method incorporates techniques and principles during the phase of data collection [15]. In one of the previous studies by P. Muray et al., [16], it was documented that the DoE optimization technique is advantageous because it gives insight into a cause and effect correlation between or among variables, eventually supporting the processes of input management and optimization before reaching the production stage [17, 18]. As such, this study applies the DoE's factorial technique to gain insight into the operation of various parameters. Particularly, the approach is applied to the Pus foams to establish the correlation between factors that affect PU foam composite responses.

\section{METHODOLOGY}

As indicated in Figure 1, a one-shot technique was employed towards polymer preparation. To prepare the composite and the polymer foam, both the cross linker and the polyols were mixed. The ratio at which

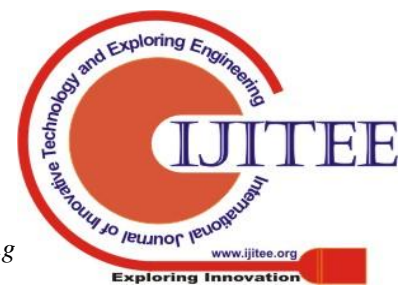


they were mixed stood at 1:2. The steps involved is started with the step (i), the polyol were pour in the plastic container, (ii) added fiber filler: flakes $(\mathrm{L})$ or powder $(\mathrm{P})$ with $(0 \%, 5 \%$, $10 \%, 15 \%$ or $20 \%$ ) of matrix weights ratios. Then, (iii) the isocyanate was poured in the mixture and vigorous stirred (iv) for 30 seconds and (v) left at room temperature to expand and cure for 24 hours. Upon curing, the samples were cut using knife and cylindrical shape for acoustical test purpose [18].

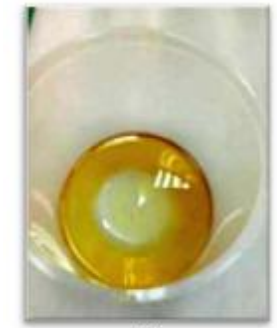

(i)

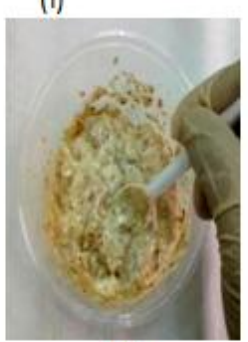

(iv)

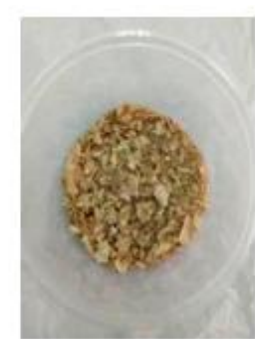

(ii)

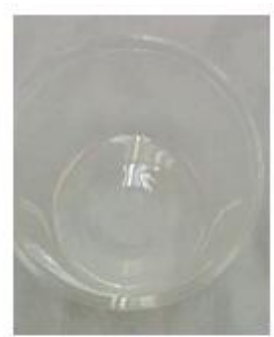

(iii)

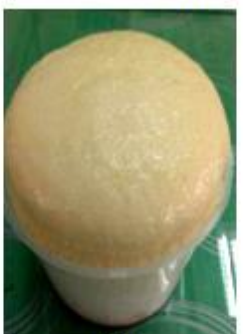

(v)
Fig. 1: Schematic diagram of PUs foam composite fabrication

To ensure that the fabricated PU foams' operatory conditions were optimized, the DoE's factorial technique of design was implemented [18]. The target input factors included X4, X, $\mathrm{X} 2$ and X1 (see Table 1). With level numbers set at 3, 2, 5 and 2 , the experiment's designed matrix was applied to a full factorial design (see Figure 2).

From the various alternative blowing agents that would be used in the place of those deemed environmentally hazardous, water becomes a promising alternative. This outcome is informed by its significant impact on the performance of the PU foams. Also, the environmental friendliness and cost-effectiveness of water account for its growing use. It is further notable that the carbon dioxide emanating from the water is not toxic and, instead, yields improvements in material properties such as thermal conductivity and density. To produce natural polyols, water is mixed with monomers. In the presence of hydroxyl groups $(\mathrm{OH})$, it is expected that the solution reacts with the isocyanate [19].

Table I: Input Factors

\begin{tabular}{lll}
\hline \hline Factors & Name & Level \\
\hline X1 & Monomer type & E-epoxy, B-bioepoxy \\
X2 & Filler ratio (\%) & $0,5,10,15,20$ \\
X3 & Filler type & L-flakes, P-powder \\
X4 & Sample Thickness & $10,20,30$ \\
\hline
\end{tabular}

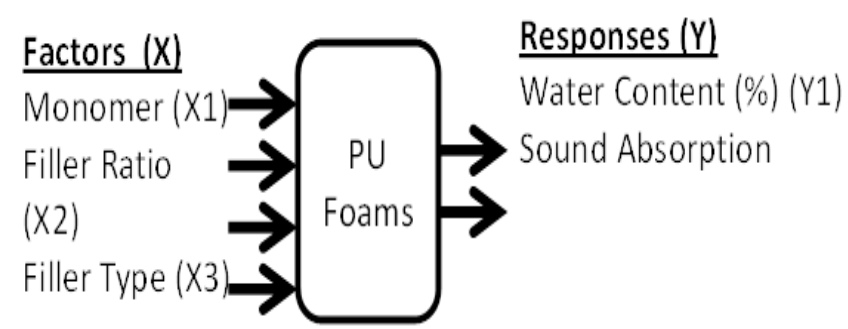

Fig. 2: PUs foams factors and responses

Loss on drying (LOD) method is a widely used test method to determine the moisture content of a sample [20]. Moisture test was conducted using Moisture Analyzer - Adam Equipment - PMB 53 as in Fig. 3 and then were analyzed the effects of water contents on the acoustical properties of the PU foams. The moisture/water content of the samples was examined using, loss on drying (LOD) moisture meter method as shown in (1). The sample is weighed, dried, and weighed again. The difference in the two weights is then compared with either the initial mass or dry mass and the moisture content calculated.

$$
\% \text { moisture }=100 * \frac{\left(\text { initial_mass }-d r y \_ \text {mass }\right)}{(\text { initial_mass })} \text { (1) }
$$

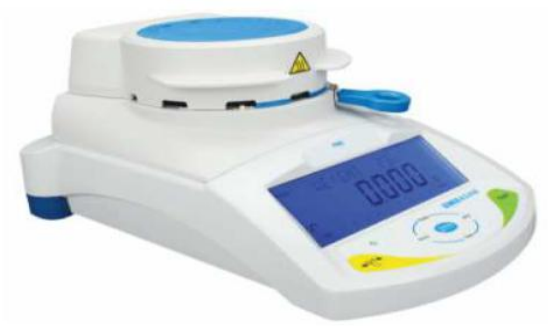

Fig. 3: Moisture Analyzer - Adam Equipment - PMB 53

To determine the coefficient of sound absorption, different types of the Tube Impedance Kit were used (see Figure 4). Also, a two-microphone impedance tube was used to calculate the coefficient of sound absorption [21]. For the PU foam and its sound absorption state, the absorption level frequencies, which were also used to calculate determine the behavior of the composite, were set between 0 and $6000 \mathrm{~Hz}$. For the selected cylindrical samples, $100 \mathrm{~mm}$ was set as the diameter. Additional experimental conditions saw a low frequency range set between 100 and $2000 \mathrm{~Hz}$. In relation to the high frequency range, which was set between 200 and $6000 \mathrm{~Hz}$, the diameter of the target samples was $28 \mathrm{~mm}$. imperative to note is that in all the investigations, the thickness of the selected samples stood at $30 \mathrm{~mm}, 20 \mathrm{~mm}$, and $10 \mathrm{~mm}$. 


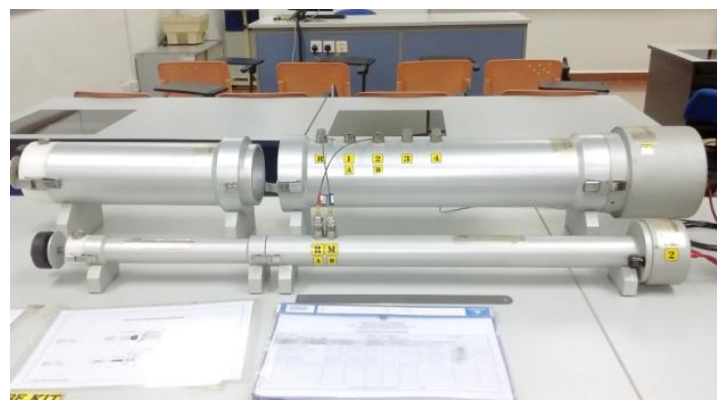

Fig. 4: Tube Impedance Kit types SSC 9020 B/K \& SSC 9020 B/TL (ASTM E1050)

\section{RESULT AND DISCUSSIONS}

A. Main effects and interaction plot for moisture content

Fig. 5 shows the effects of input factors monomer type (X1), filler ratio (X2) and filler type (X3) in polymer foam production were analyzed to investigate the water content (\%) (Y1) in the PUs foam. The fabricated PUs foam and its composites based on waste vegetable oil bio-epoxy (B) gives higher moisture content (\%) as compare to petroleum based synthetic epoxy (E). The factor, X2 of filler ratio shows inconsistent effect to the moisture content. This also revealed that the smaller size of fiber filler (powder); $\mathrm{P}$ has little effect on the moisture content (\% (Y1)).

The matrix interaction plots for moisture content $(\%)$ in Fig. 6 shows the mean response for all full interaction between 3 input factors monomer type (X1), filler ratio (X2) and filler type (X3). With 3 input factors, there are 6 possible ways to create an interaction plot. The interaction effect indicates that the relationship between filler ratio and moisture content depends on the type of monomer, B or E. It appears that, there are interactions between monomer (X1) and filler ratio (X2); since a change to one factor cause the effect of another factor to change. PU foams fabricated with bio-epoxy (B) with lower filler ratio have higher moisture content (\%) while synthetic epoxy (E) based Pus foam with higher filler ratio (X2) have higher moisture content $(\%)$. However, monomer (X1) and filler type (X3) interaction plots are in parallel lines shows that there is no interaction between monomer (X1) and filler type (X3).

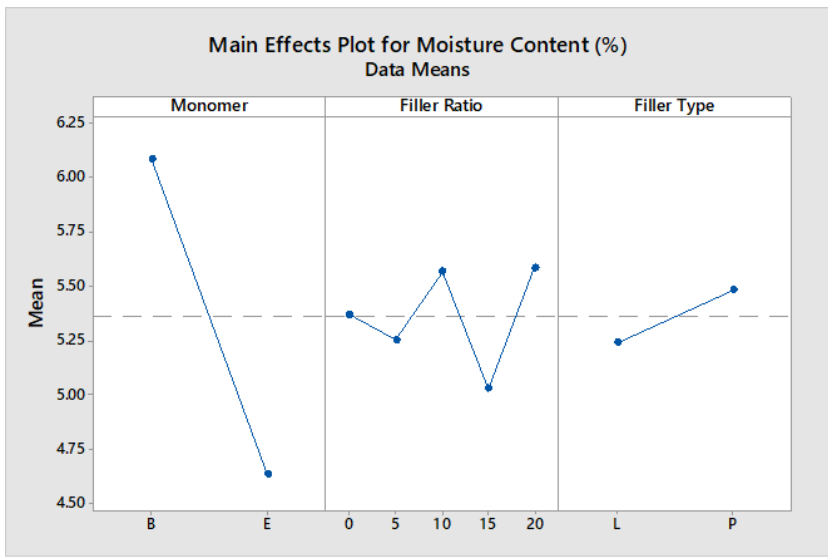

Fig. 5: Main effects plot for moisture content, (Y1)(\%)

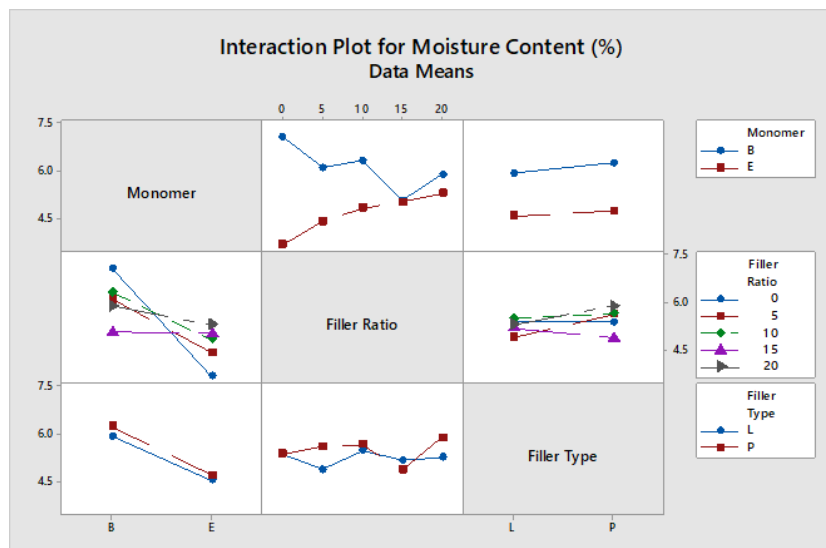

Fig. 6: Interaction plot matrix for moisture content, (Y1)(\%)

\section{B. Main Effects and Interaction Plots for Sound Absorption Coefficient, $\alpha$}

To determine the coefficient of sound absorption, factors that were consider, which formed the independent variables, included the thickness of the sample (X4), the type of the filler (X3), the ratio of the filler (X2), and the type of the monomer (X1). Figure 7 show the absorption level as set at a low frequency. Particularly, the range of this frequency was set between $500 \mathrm{~Hz}$ and $1000 \mathrm{~Hz}$. The figure gives insight into the state of the monomer type X1. Regarding the ratio of the filler, the results suggest that thee parameter poses an inconsistent impact on the coefficient of absorption; with the latter results obtained after setting the frequency at $1000 \mathrm{~Hz}$.

Relative to the type of the filler and its impact on the coefficient of sound absorption, it is evident that a nearly equal value is obtained when a comparative analysis of the powder filler and PU foam containing flakes is conducted. However, an increase in the thickness of the sample is observed to reduce the coefficient of material sound absorption. At a frequency set in the range between $1500 \mathrm{~Hz}$ and $2000 \mathrm{~Hz}$, additional results suggest that the E monomer exhibits a lower value compared to a case in which the $\mathrm{B}$ monomer is used. However, an increase in the ratio of the filler causes an increase in the coefficient of sound absorption, suggesting that the two variables exhibit a positive or direct relationship.

It was notable further that an increase in the size of the filler would increase the coefficient of material sound absorption. For the PU foam, however, an increase in the thickness of the sample did not have a significant effect in the coefficient of material sound absorption. At $1500 \mathrm{~Hz}$, it is notable that there is elastic collision; hence less incident energy is lost. The eventuality is that the coefficient of sound absorption decreases.

When the frequency level was set at medium to high, which stood between $2500 \mathrm{~Hz}$ and $4000 \mathrm{~Hz}$ (see Figure 8), findings regarding the $\mathrm{X} 1$ type of monomer indicated that there is a maximum increase in the coefficient of material sound absorption with an increase in the ratio of the filler. Also, the impact posed by the power filler was observed to be lower than that which was felt when the PU foams with flakes were used as the fillers. Additional investigations focused on material behavior and relationships between and among variables when a high 
level of frequency was used as part of the experimental conditions, under these conditions, which ranged from 4500 $\mathrm{Hz}$ to $6000 \mathrm{~Hz}$ (see Figure 9), the B monomer exhibited a lower coefficient of sound absorption compared to the $\mathrm{E}$ monomer. Also, an increase in the ratio of the filler was observed to cause an increase in the coefficient of sound absorption; hence a direct relationship. Similarly, the powder filler exhibited lower values of the coefficient of sound absorption than the PU foams containing the L filler. Given maximum sample thickness in these experimental conditions (that involved high frequency levels), the value of the coefficient of sound absorption increase in X4. At $6000 \mathrm{~Hz}$, there was a gradual decrease in the value of the coefficient of sound absorption.

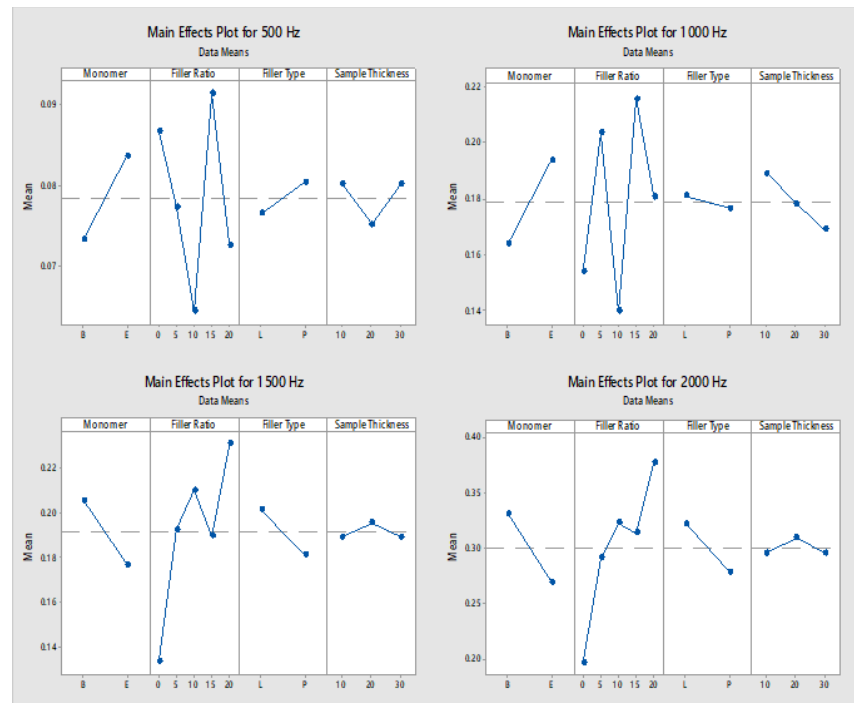

Fig. 7: Main effects plot for sound absorption coefficient response, (Y2) at low frequency $(500-2000 \mathrm{~Hz})$

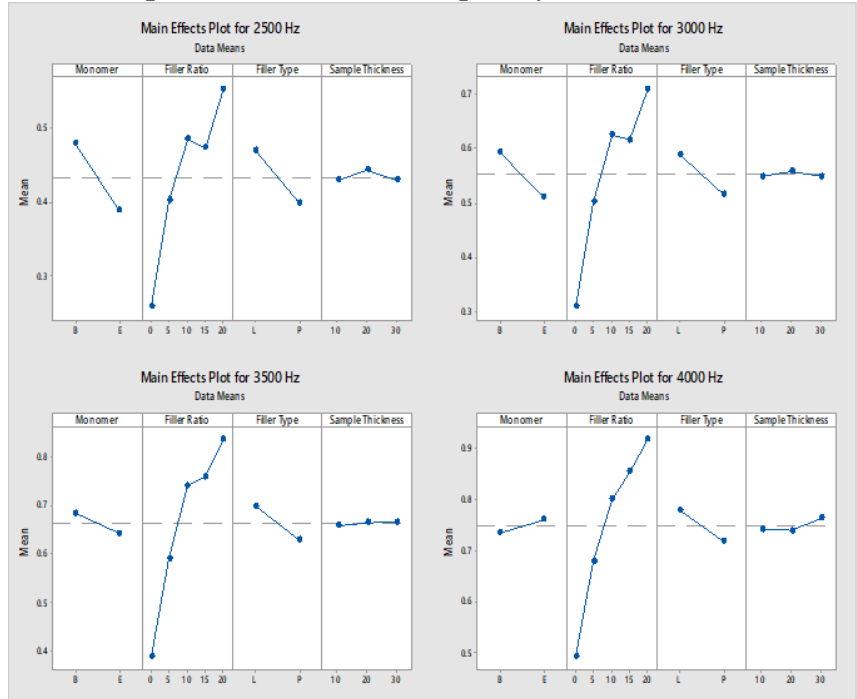

Fig. 8: Main effects plot for sound absorption coefficient response, (Y2) at medium high frequency $(2500-4000 \mathrm{~Hz})$

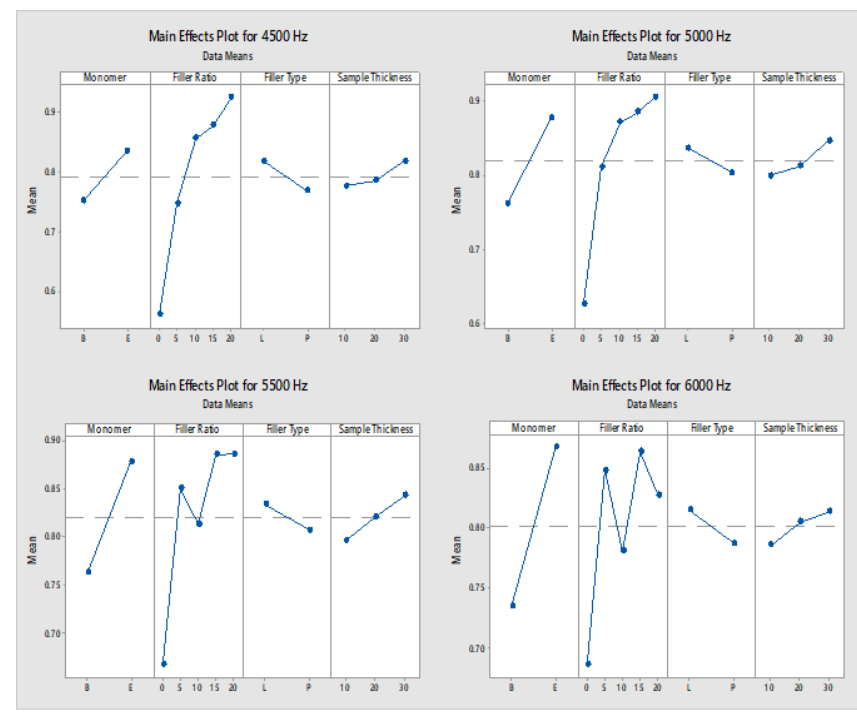

Fig.9: Main effects plot for sound absorption coefficient response, (Y2) at high frequency $(4500-6000 \mathrm{~Hz})$

The matrix interaction plots for the low $(1000 \mathrm{~Hz})$ and high $(5500 \mathrm{~Hz})$ frequency level of sound absorption coefficient, $\alpha$ is shows in Fig. 10 and Fig 11. At low frequency $(1000 \mathrm{~Hz})$, Fig. 9 shows the effect of filler type (X3) on the $\alpha$ response depend on the level of filler ratio (X2) ( at 20\%) and the effect of filler ratio (X2) depends on the level of filler type (X3). This type of behavior occurs when a significant interaction exists between 2 variables. The plot shows that there is a significant difference in the $\alpha$ response between monomer type (X1) B and E. There appear to be significant main effects associated with monomer type (X1), filler ratio (X2) and sample thickness (X4). There is also a significant interaction between the two variables indicated by the diverging line segment between sample thickness $=20$ to $30 \mathrm{~mm}$ and filler ratio $=15$ to $20 \%$. However, there is no significant interaction between sample thickness (X4) andfiller type (X3) and between filler type (X3) and monomer (X1).

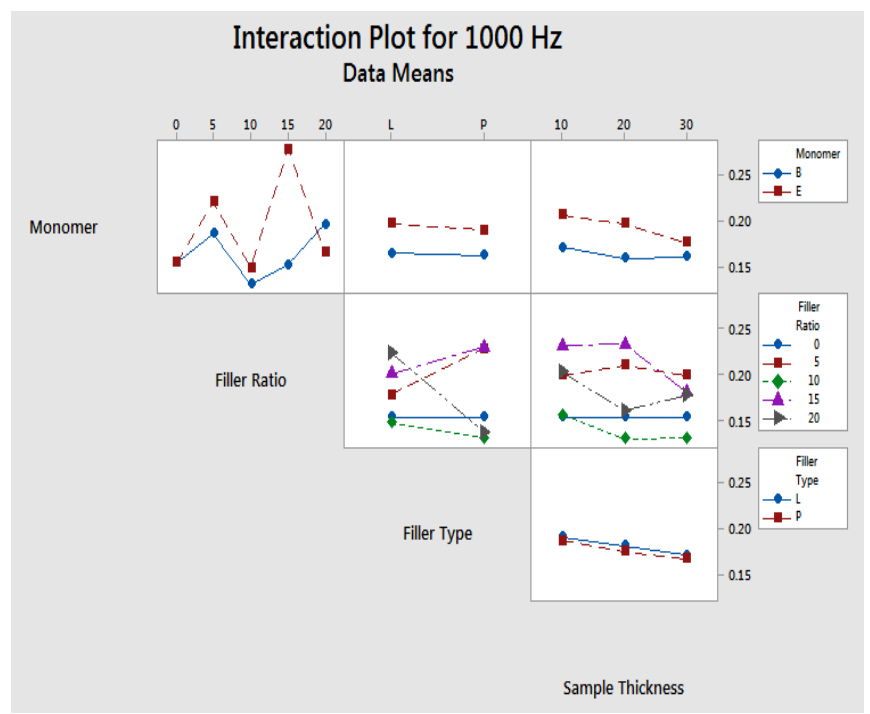

Fig. 10: Interaction plot matrix for sound absorption coefficient response, (Y2) at low frequency $(1000 \mathrm{~Hz})$ 


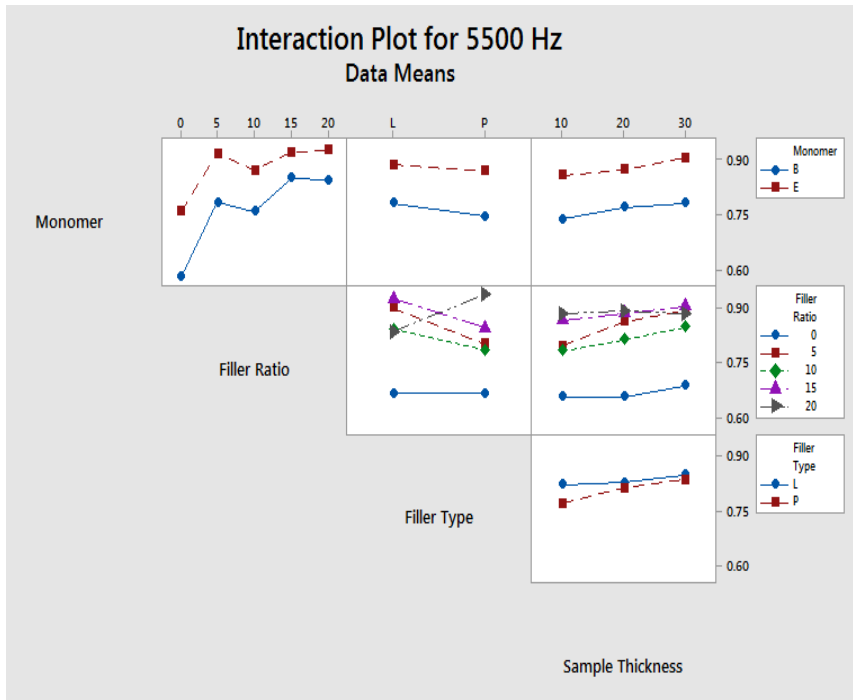

Fig. 11: Interaction plot matrix for sound absorption coefficient response, (Y2) at high frequency $(5500 \mathrm{~Hz})$

At higher level frequency $(5500 \mathrm{~Hz})$, Fig. 10 shows that there is a significant difference in the aresponse (Y2) between B and $\mathrm{E}$ monomer (X1) and that the highest (20\%) filler ratio(X2) does appear to deliver a the highest $\alpha$ value. There is no main significant interaction between simple thickness (X4) and monomer (X1) and between filler type (X3) and monomer (X1). There appear to be significant main effects associated between the filler type (X3) and sample thickness (X4)indicated by the diverging line segment between sample thickness $=20$ to $30 \mathrm{~mm}$.

\section{CONCLUSION}

PUs foams fabricated with waste vegetable based bio-epoxy (B) represents an alternative renewable resource. The fabricated PUs foam based on waste vegetable oil bio-epoxy (B) gives higher moisture content (\%) as compare to petroleum based synthetic epoxy (E). Regarding the coefficient of the sound absorption response, higher filler ratios and larger filler sizes are seen to increase the coefficient value of the maximum sound absorption. The latter results are seen to hold when the frequency level is low. Under high frequency level, the maximum coefficient value of the sound absorption is achieved when the experimental conditions are characterized by increased sample thickness, the presence of the highest filler ratio, and the presence of larger-sized filler. In conclusion, the study indicated that PU is a promising material for sound absorption; especially due to its high porosity and low density. In future, there is a need for scholarly investigations to determine the role of water content in shaping the PU pore structure's state of morphology, upon which the material's nature of acoustic performance could be predicted.

\section{ACKNOWLEDGMENT}

Several groups, organizations, and people are acknowledged for their contributory role towards realizing the success of this study. They include the Ministry of Education Malaysia, Johor, University Tun Hussein Onn Malaysia (UTHM), Advanced Manufacturing and Materials Centre (SPEN-AMMC), and Sustainable Polymer Engineering.

\section{REFERENCES}

[1] L. Peng, B. Song, J. Wang, and D. Wang, "Mechanic and acoustic properties of the sound-absorbing material made from natural fiber and polyester," Adv. Mater. Sci. Eng., 2015.

[2] E. M. Samsudin, L. H. Ismail, and A. A. Kadir, "A review on physical factors influencing absorption performance of fibrous sound absorption material from natural fibers," ARPN Journal of Engineering and Applied Sciences. 2016.

[3] S. Liu, W. Chen, and Y. Zhang, "Design optimization of porous fibrous material for maximizing absorption of sounds under set frequency bands," Appl. Acoust., 2014.

[4] L. Egab, X. Wang, and M. Fard, "Acoustical characterisation of porous sound absorbing materials: a review," Int. J. Veh. Noise Vib., 2014.

[5] S. Chen, X. Lu, T. Wang, and Z. Zhang, "Preparation and characterization of urea-formaldehyde resin/reactive kaolinite composites," Particuology, 2016.

[6] S. Amares, E. Sujatmika, T. W. Hong, R. Durairaj, and H. S. H. B. Hamid, "A Review: Characteristics of Noise Absorption Material," in Journal of Physics: Conference Series, 2017.

[7] R. Gayathri and R. Vasanthakumari, "Nanomaterials in PU Foam for Enhanced Sound Absorption at Low Frequency Region,” Adv. Mater. Res., 2014.

[8] J. G. Gwon, S. K. Kim, and J. H. Kim, "Sound absorption behavior of flexible polyurethane foams with distinct cellular structures," Quat. Int., 2015 .

[9] S. Adnan et al., "Development of Flexible Polyurethane Nanostructured Biocomposite Foams Derived from Palm Olein-Based Polyol," Adv. Mater. Sci. Eng., 2016.

[10] S. Kormin, A. Z. M. Rus, and M. S. M. Azahari, "Preparation of polyurethane foams using liquefied oil palm mesocarp fibre (OPMF) and renewable monomer from waste cooking oil," in AIP Conference Proceedings, 2017.

[11] A. Z. M. Rus, M. S. M. Azahari, S. Kormin, L. B. Soon, M T. Zaliran, and M. L. F. Ahraz Sadrina, "Hybrid waste filler filled bio-polymer foam composites for sound absorbent materials," in AIP Conference Proceedings, 2017.

[12] E. Papa et al., "Porosity and insulating properties of silica-fume based foams," Energy Build., 2016.

[13] M. N. A. A. Nordin, L. M. Wan, M. H. Zainulabidin, A. S. M. Kassim, and A. M. Aripin, "Research finding in natural fibers sound absorbing material," ARPN J. Eng. Appl. Sci., 2016.

[14] Y. Jiang, S. Chen, D. Wang, and J. Chen, "Multi-Objective Optimization of Acoustical Properties of PU-Bamboo-Chips Foam Composites," Arch. Acoust., 2017.

[15] M. Barad, "Design of Experiments (DOE)-A Valuable Multi-Purpose Methodology," Appl. Math., 2014.

[16] P. M. Murray, F. Bellany, L. Benhamou, D. K. Bučar, A. B. Tabor, and T. D. Sheppard, "The application of design of experiments (DoE) reaction optimisation and solvent selection in the development of new synthetic chemistry," Organic and Biomolecular Chemistry. 2016.

[17] J. Y. Lau, M. H. T. Nguyen, W. Liang, and K. K. Tan, "Application of design of experiments to feature selection in ventilation tube applicator," in IECON 2015 - 41st Annual Conference of the IEEE Industrial Electronics Society, 2015.

[18] Abd Wahab, Hanani, Anika Zafiah Mohd Rus, \& M. Taufiq Zaliran "Design of Experiment for In-Situ Synthesis of Waste Vegetable Oils and Synthetic Based Polyurethane (PU) Foam Composites." International Journal of Engineering \& Technology [Online], 7.4.34 (2018): 413-416. Web. 7 Mar. 2019

[19] N. N. M. Hassan and A. Z. M. Rus, "Acoustic performance of green polymer foam from renewable resources after UV exposure," Int. J. Automot. Mech. Eng., 2014.

[20] S. Bell, N. Boese, R. Bosma, M. Buzoianu, P. Carroll, V. Fernicola, E Georgin, M. Heinonen, A. Kentved, C. Melvad and J. Nielsen, METefnet: developments in metrology for moisture in materials. 2015.

[21] N. Q. A. Adnan and A. Z. M. Rus, "Sound Absorption of Laminated BiopolymerFoam and Epoxy Foam," Key Eng. Mater., vol. 594-595, pp. 291-295, 2014.

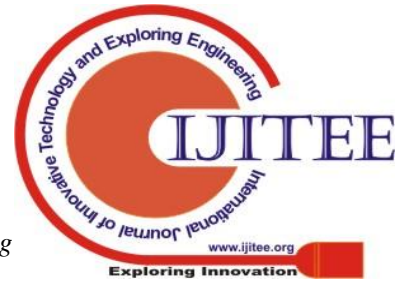




\section{AUTHORS PROFILE}

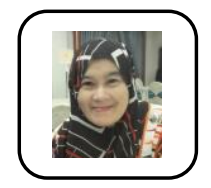

Hanani Abdul Wahab is a lecturer in Faculty of Mechanical and Manufacturing Engineering at the University of Tun Hussein Onn Malaysia (UTHM). She obtained Msc. in Mechatronics Engineering in 2007 from International Islamic University Malaysia (IIUM) and BEng of Artificial Intelligence System Engineering in 2001 from Kyushu Institute of Technology (KIT), Japan. She had more than 10 years experience of teaching and researches in higher education. Her interest is in control system strategies and optimization which can be used in solutions to many engineering problems.nani@uthm.edu.my

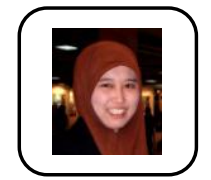

Anika Zafiah Mohd Rus is an Associate Professor in the Faculty of Mechanical and Manufacturing Engineering at the University of Tun Hussein Onn Malaysia (UTHM). She obtained her $\mathrm{PhD}$ in March 2007 from University of Warwick, United Kingdom in Polymer Chemistry and Engineering, BSc (Hons) in Mechanical Engineering (Manufacturing) in 1998 and MSc in Technical and Vocational in 1999 from University of Technology Malaysia (UTM), and her Diploma in Rubber and Plastics Technology from University of Technology MARA (UiTM) in 1993. At the present she's a the Principle Researcher in the Advanced Manufacturing and Materials Center (AMMC), Faculty of Mechanical and Manufacturing Engineering. She had more than 10 years experience of teaching in higher education in Polytechnic and UTHM, which involved teaching in Electrical Technology, Engineering Sciences, Micro Teaching, Mechanical Engineering Skills, Materials Science, Engineering Materials Selection, Mechanical Engineering Design, Engineering Polymer and Advanced Polymer. zafiah@uthm.edu.my

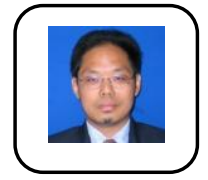

Mohammad Faiz Liew Abdullah is a Professor in the Faculty of Electrical and Electronic Engineering at the University of Tun Hussein Onn Malaysia (UTHM). He completed his $\mathrm{PhD}$ in August 2007 from University of Warwick, United Kingdom in Wireless Optical Communication Engineering. He received MEng by research in Optical Fiber Communication in 2000, BSc (Hons) in Electrical Engineering (Communication) in 1997 and Dip Education in 1999 from University of Technology Malaysia (UTM). He had 15 years experience of teaching in higher education, which involved the subject Optical Fiber Communication, Advanced Optical Communication, Advanced Digital Signal Processing and etc. His research area of interest are wireless and optical communication, photonics and robotic in communication.

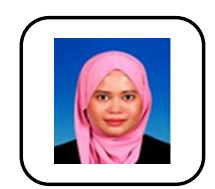

Nur Munirah Abdullah is currently a $\mathrm{PhD}$ student in Mechanical Engineering (Materials) from Universiti Tun Hussein Onn Malaysia (UTHM), Malaysia under the supervision of Associate Professor Dr. Anika Zafiah bt Mohd Rus and Associate Professor Dr. Muhammad Faiz Liew bin Abdullah. Her research purpose is centered on graphite/ renewable polymer conductive composites. Before that, she received M.A. (by Research) in Mechanical Engineering (Materials) from Universiti Tun Hussein Onn Malaysia (UTHM), Malaysia (2012) based on semiconductor materials with organic dye as sensitizer for dye-sensitized solar cell application whilst BSc. (Hons.) in Physics from Universiti Putra Malaysia (UPM), Malaysia (2009) focusing on dielectric properties of organic materials.nurmunirahabdullah87@gmail.com 